\title{
Treated Tropical Wood Sawdust-Polypropylene Polymer Composite: Mechanical and Morphological Study
}

\author{
Muhammad Abdul Mun'aim Mohd Idrus*, Sinin Hamdan, Muhammad Rezaur Rahman, \\ Muhammad Ssiful Islam \\ Department of Mechanical and Manufacturing Engineering, Faculty of Engineering, University Malaysia Sarawak, Kota Samarahan, \\ Malaysia. \\ Email: ${ }^{*}$ mambi86@gmail.com
}

Received June $4^{\text {th }}, 2011$; revised July $22^{\text {nd }}, 2011$; accepted September $27^{\text {th }}, 2011$.

\begin{abstract}
In this research, composites based on treated tropical sawdust and polypropylene $(P P)$ were prepared using hot press molding machine. Raw sawdust was chemically treated with monomer, 2-ethylhexyl methacrylate in order to improve the mechanical properties of the composites. The influence of the chemically treated sawdust on the physical and mechanical properties of sawdust-PP composites were investigated at various loading level from $10 \mathrm{wt} \%$ up to 30 wt $\%$. Results indicate that the mechanical properties of the chemically treated sawdust-PP composites were found to be higher than those of the raw ones respectively. The surface morphology obtained from scanning electron microscopy (SEM) showed that raw sawdust-PP composites possess surface roughness and weak interfacial adhesion between the matrix and the filler while the chemically treated one showed improved filler-matrix interaction. This indicates that better dispersion of the filler with the PP matrix has occurred upon chemical treatment of the filler. Water absorption tests showed that composites prepared from the chemically treated sawdust absorb lower amount of water compared to the ones prepared from raw sawdust, suggesting that hydrophilic nature of the cellulose in the sawdust has significantly decreased upon chemical treatment.
\end{abstract}

Keywords: Wood Sawdust, Polypropylene, Mechanical Properties, Water Absorption

\section{Introduction}

Recently many production and application of thermoplastic polymer composites are being made by combining with various reinforcing fillers fiber such as sawdust/ wood flour was increased. Materials such as sawdust can replace and reduce the utilization of plastic which relate with the environmental issue and also offer other advantage. Sawdust is obtained from natural resources and in a large amount from wood industry as a waste. Although the used of sawdust not very popular for WPC, but basically this material is light, cheap; stiffness and it can be added to commodity matrix in certain loading level hence offering one of the best solutions for the utilization of waste wood and cheap product [1]. The uses of natural fibers-reinforced thermoplastics are increased in recent years such as in automotive, cosmetics, and plastics lumber applications for furniture and housing. In wood industries such as timber and furniture, large amounts of sawdust are always found as waste. Basically these sawdust are used as a fuel source or used to make others fur- niture product such as plywood. Especially in Borneo island Sarawak. There is a lot of sawdust abundantly available from the industries.

Thus, studies on the improvement of sawdust-PP composites (WPCs) have been actively followed and done not only in industry but also in academic research field. The sawdust used in WPC in place of the longer individual wood fibers is most often added in particulate form from $10 \mathrm{wt} \%$ up to the $50 \mathrm{wt} \%$ loading level by weight. Because of the high availability and low cost of the sawdust, it can be more useful and valuable by mixing sawdust with polymer in order to improve the mechanical properties of the composites. In the related literature, it has been reported that most polymer composites involved fiber reinforcement, for instance from jute fibers, bamboo fibers, oil palm empty fruits, corn fibers and many more [2-5]. The main application area of sawdust filled composites is the building and automotive industry $[1,6]$, but they are also applied for packaging, for the preparation of various household articles, furniture, office appliances and other items [7]. However, 
although the use of sawdust in polymer composites has several advantages over inorganic fillers, the hydrophilic characteristic nature of the wood has a negative effect and brings difficulties in obtaining good dispersion of the wood particles and poor reinforcement between sawdust and polymer. The sawdust is polar and polymer non polar has leads to incompatibility problem between the materials. Hence affect the mechanical and physical properties of the composites [8]. Interfacial interactions are very weak in sawdust fiber filled composites, because the surface free energy of both the filler and the polymer is very small [9]. The interface between the polymer matrix and natural filler are very poor [3]. Furthermore the natural fibers such as sawdust increase the water absorption or desorption of composites when exposed to changes in the relative humidity of the environment. Sawdust has a better natural tendency due to a natural structure made of cellulose fibers in an amorphous matrix of hemicellulose and lignin. Cellulose is the main fundamental of the cell wall of the wood, has many hydroxyl group that are strongly hydrophilic [10]. Therefore, there is much attention has been on the run by modification or treated of the filler by physical and chemical methods to improve the filler-matrix interaction in order to achieved acceptable properties. Various techniques are used or at least tried for the improvement of interfacial adhesion including the coupling of sawdust with functional silanes or the coating of wood flour with stearic acid and the treatment of wood with sodium hydroxide [11-13]. Kuruvila and Sabu have studied the effect of chemical treatments with alkali, permanganate, isocyanate and peroxide on the tensile properties of short sisal fiber-reinforced polyethylene composites. They reported a considerable improvement of the tensile properties of composites [14]. Also from the previous research, the mechanical properties of natural fibers reinforced polymer such as Young's Modulus and flexural strength can be enhanced significantly by using method pre-treating with sodium periodate and post-treating with urotropine and urea [15].

In the present work, the raw tropical sawdust was treated with 2-ethylhexyl methacrylate to increase the compatibility of the tropical sawdust with the PP matrix. Thus, the aim of this study is to manufacture composites from raw and treated tropical sawdust and polymer PP at different loading and subsequently characterize those using the microstructural analysis and mechanical testing. The effects of tropical sawdust loading on the mechanical properties and morphology of the sawdust reinforced PP composites are also reported.

\section{Experimental}

\subsection{Materials}

Wood sawdust from selected tropical softwood was used in this investigation (Eugenia spp, Artocarpus rigidus, Artocarpus elasticus, Koompassia malaccensis, and $\mathrm{Xy}-$ lopia spp). The wood was sawn using a laboratory table saw and the sawdust was collected. The sawdust was then oven dried at $70^{\circ} \mathrm{C}-80^{\circ} \mathrm{C}$ to a moisture content of $3 \%-5 \%$, then stored in polyethylene bag until needed. The sawdust, used as reinforcing filler, was received from external laboratory of faculty of FSTS, UNIMAS. Polypropylene's (PP which was used as polymer matrix, has a melt index of $0.28 \mathrm{~g} / 10 \mathrm{~min}$ with a density of 0.938 $\mathrm{g} / \mathrm{cm} 3$. PP was supplied by Korea Petrochemical Ind. Co., LTD.

\subsection{Sample Preparation}

The wood was sawn using a laboratory table saw and the Wood sawdust was collected. The sawdust was then oven dried at $70^{\circ} \mathrm{C}-80^{\circ} \mathrm{C}$ to a moisture content of $3 \%$ $5 \%$, then stored in polyethylene bag until needed. The particle sizes of the sawdust were in the range between 80 and 100 mesh. Chemicals used to treat sawdust were 2-ethylhexyle methacrylate supplied by merck shurchardt OHG, Germany and sulphuric acid (H2SO4) was used as the catalyst and its content was $5 \%$, based on the amount of the main chemical.

\subsection{Treatment of Sawdust}

Before treatment the sawdust was dried at $105^{\circ} \mathrm{C}$ for about $24 \mathrm{~h}$ until constant weight was reached to obtain $1 \%-2 \%$ moisture content and then kept in a sealed container. $200 \mathrm{~mL}$ 2-ethylhexyl methacrylate, $\left(\mathrm{C}_{12} \mathrm{H}_{22} \mathrm{O}_{2}\right)$ solution was taken in a $500 \mathrm{~mL}$ beaker. $500 \mathrm{~g}$ of sawdust was submerged into the solution for about 1 hour at about $70^{\circ} \mathrm{C}$ in an oven. After about 1 hour, sawdust was taken out of the beaker, washed by water and finally dried in open air.

The monomer 2-ethylhexyl methacrylate was used for chemical modification of wood sawdust and its main polymer components. This chemical containing (as in scheme 1) the functional groups of $\mathrm{C}_{12} \mathrm{H}_{22} \mathrm{O}_{2}$ monomer was interact with the polar groups mainly hydroxyl groups (-OH) of cellulose and lignin to form covalent or hydrogen bonding. It is expected that, there will be remaining groups of hydroxyl as it is cannot be eliminate all together because of the strong bonding. These project main focusing is to reduce the number of hydroxyl groups in the cellulose and lignin as the high contain number of hydroxyl groups will lead to a weaken adhesion bonding with the polymer matrix and vice versa.

\subsection{Manufacturing of Wood Flour-PP Polymer Composites}

The WPC were prepared from raw and treated sawdust and PP. The sawdust was mixed with PP in a beaker at 5 


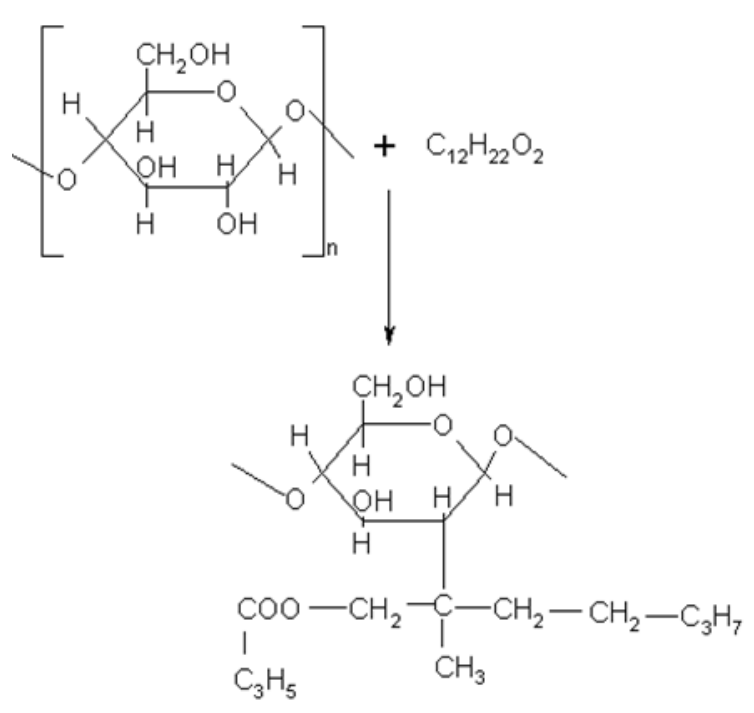

Scheme 1. Treatment of Cellulose in sawdust with 2-ethylhexyle methacrylate.

different ratios; $10 \%, 15 \%, 20 \%, 25 \%$ and $30 \%$ by weight. The mixtures were stirred continuously until uniformly mixed without any external heating and then pre heated in an oven for 24 hour at $80^{\circ} \mathrm{C}$ to ensure the mixing is adequate. The mixture was compression molded into a sheet measuring $270 \mathrm{~mm} \times 270 \mathrm{~mm} \times 5 \mathrm{~mm}$ at temperatures $200^{\circ} \mathrm{C} \pm 5^{\circ} \mathrm{C}$. Then this molding board was cut to the test specimen size appropriate for each test. The molding conditions were as follows; pressure, 6.8 $\mathrm{MPa}$, preheating time, $20 \mathrm{~s}$; heating time, $45 \mathrm{~min}$; and cooling under a slight pressure to ambient temperature.

\subsection{Micro Structural Analysis}

\subsubsection{Fourier Transform Infrared Spectroscopy (FTIR)}

The infrared spectra of the raw sawdust, treated sawdust specimens were recorded on a Shimadzu Fourier Transform Infrared Spectroscopy (FTIR) 81001 Spectrophotometer. The transmittance range of the scan was 4000 to $400 \mathrm{~cm}^{-1}$. The obtained spectra are described in the results and discussions section.

\subsubsection{Scanning Electron Microscopy}

The surfaces morphology of the tropical WF-PP and interfacial adhesion between the filler and the PP matrix was examined by a scanning electron microscopy (JSM5510, JEOL Co. Ltd., Japan). The samples were sputter coated with platinum and observed under the SEM. The micrographs were taken at a magnification of 300 .

\subsection{Mechanical Testing}

Tensile, flexural, hardness and water absorption tests were conducted to observe the physical and mechanical properties of the raw and treated WPC.

\subsubsection{Tensile Test}

The tensile tests were carried out following ASTM D 638-01 [16] using a Universal Shimadzu tensile machine and each test was performed at a crosshead speed of 10 $\mathrm{mm} / \mathrm{min}$. For each test, five replicates samples were tested and the average values were reported.

\subsubsection{Flexural Test}

Three points bending test were conducted following ASTM D 790-00 [17] using the same testing machine mentioned above at same crosshead speed. The dimension of the specimen was $79 \mathrm{~mm} \times 10 \mathrm{~mm} \times 4.1 \mathrm{~mm}$. For each test, five replicates samples were tested and the average values were reported. To measure modulus of elasticity (MOE) and flexural strength, the following equation are using;

$$
\begin{aligned}
& \text { Flexural Strength, } \sigma=(3 \mathrm{PL} / 2 \mathrm{bd}) \\
& \text { Flexural Modulus, } E=\left(\mathrm{L}^{3} \mathrm{~m} / 4 \mathrm{bd}^{3}\right)
\end{aligned}
$$

where $\mathrm{P}$ is the maximum applied load, $\mathrm{L}$ is the length of support span, $\mathrm{m}$ is the slope of the tangent, $\mathrm{b}$ and $\mathrm{d}$ are the width and thickness of the specimen, respectively.

\subsubsection{Hardness Test}

The hardness of the composites was measured using a Rockwell Hardness Testing Machine according to ASTM D785-98 [18]. For each test, five replicates samples were tested and the average values were reported. Results are shown in the following section.

\subsubsection{Dimensional Stability}

Raw and treated sawdust-PP samples of dimensions 40 $\mathrm{mm} \times 10 \mathrm{~mm} \times 4.1 \mathrm{~mm}$ were prepared for the measurement of water absorption and thickness swelling. The samples were air dried at $70^{\circ} \mathrm{C}$ until a constant weight was reached prior to the immersion in a static deionized water bath. Each value obtained represented at the average of five samples. The specimens were periodically taken out of the water, wiped with tissue paper to removed surface water, reweighed and dimensions re-measured and immediately put back into the water. Five replicates samples for each sample were used. Water absorption were calculated according to the formula

$$
\text { Water absorption }(\%)=\left[\left(W_{2}-W_{1}\right) / W_{1}\right] \times 100 \%
$$

where $W_{2}$ is the specimen weight after soaking and $W_{1}$ is the weight of sample before soaking. The thickness swelling coefficient (TS) is calculated as follows:

Thickness swelling coefficient,

$$
(T S)=\left[\left(T_{2}-T_{1}\right) / T_{1}\right] \times 100 \%
$$

where TS is the percent of thickness swelling and $T_{1}$ and $T_{2}$ is the thickness of the specimen before and after the test 
respectively.

\section{Results and Discussion}

\subsection{Fourier Transform Infrared Spectroscopy (FTIR)}

The formation of new chemical reaction cellulose compound by the chemical reaction with 2-ethylhexyl methacrylate was confirmed by the FTIR spectroscopic analysis of the untreated and treated wood sawdust, as shown in Figure 1.

The formation of new chemical reaction cellulose compound by the chemical reaction with 2-ethylhexyl methacrylate was confirmed by the FTIR spectroscopic analysis of the untreated and treated wood sawdust, as shown in Figure 1. The FTIR spectrum of the untreated wood sawdust clearly shows the absorption bands in the region of $3406 \mathrm{~cm}^{-1}, 2903 \mathrm{~cm}^{-1}$ and $1735 \mathrm{~cm}^{-1}$ due to $\mathrm{O}-\mathrm{H}$ stretching vibration, $\mathrm{C}-\mathrm{H}$ stretching vibration, and $\mathrm{C}=\mathrm{O}$ stretching vibration, respectively. These absorption bands are due to hydroxyl group in cellulose, carbonyl group of acetyl ester in hemicellulose, and carbonyl aldehyde in lignin [19]. The absorption band at treated sawdust show at O-H which shifted towards $3424 \mathrm{~cm}^{-1}$ and at $\mathrm{C}-\mathrm{H}$ the absorbance shifted towards into $2916 \mathrm{~cm}^{-1}$ respectively. It can be seen that, the carbonyl peak $\mathrm{C}=\mathrm{O}$ at $1735 \mathrm{~cm}^{-1}$ was slightly shifted towards $1730 \mathrm{~cm}^{-1}$ in the spectra of treated sawdust because the ester carbonyl bonds in the hemicellulose was break due to the chemical treatment. All the difference happen between the raw and treated sawdust was confirm the chemical treatment onto the sawdust.

A PP composite clearly shows the absorption bands of polymer polypropylene in the FTIR spectra. In raw sawdust composites, the PP absorption band clearly can be seen at region $2961 \mathrm{~cm}^{-1}$ belong to $\mathrm{CH}_{3}$ asymmetric and symmetric stretches, $2838 \mathrm{~cm}^{-1}$ and 2918 due to $\mathrm{CH}_{2}$ asymmetric and symmetric. Another absorption bands correspond to $\mathrm{PP}$ is at absorption band in the region 1377 $\mathrm{cm}^{-1}$ which is due to $\mathrm{CH}_{3}$ umbrella mode.

On the other hand, FTIR spectra of treated sawdust-PP composites also show the existence of PP inside the composites. Figure 2 clearly show the presence of the characteristic of PP in the region of $2960 \mathrm{~cm}^{-1}$ and $2921 \mathrm{~cm}^{-1}$, $2838 \mathrm{~cm}^{-1}$ due to the $\mathrm{CH}_{3}$ and $\mathrm{CH}_{2}$ asymmetric and symmetric stretches, also at the region $1377 \mathrm{~cm}^{-1}$ due to $\mathrm{CH}_{3}$ umbrella mode. Besides that, in the treated composites there was presence a few new absorption bands which are believed due to the chemical treatment done before [20].

\subsection{Scanning Electron Micrographs (SEM)}

Morphology of the raw sawdust-PP composites and treated sawdust-PP composites is represented in Figure 3. It has been observed that surface morphology of treated sawdust-PP composites differ in smoothness and roughness than the raw sawdust-PP composites.

Figure 3(c), (d) illustrate that the modified sawdust was well dispersed in the composites.

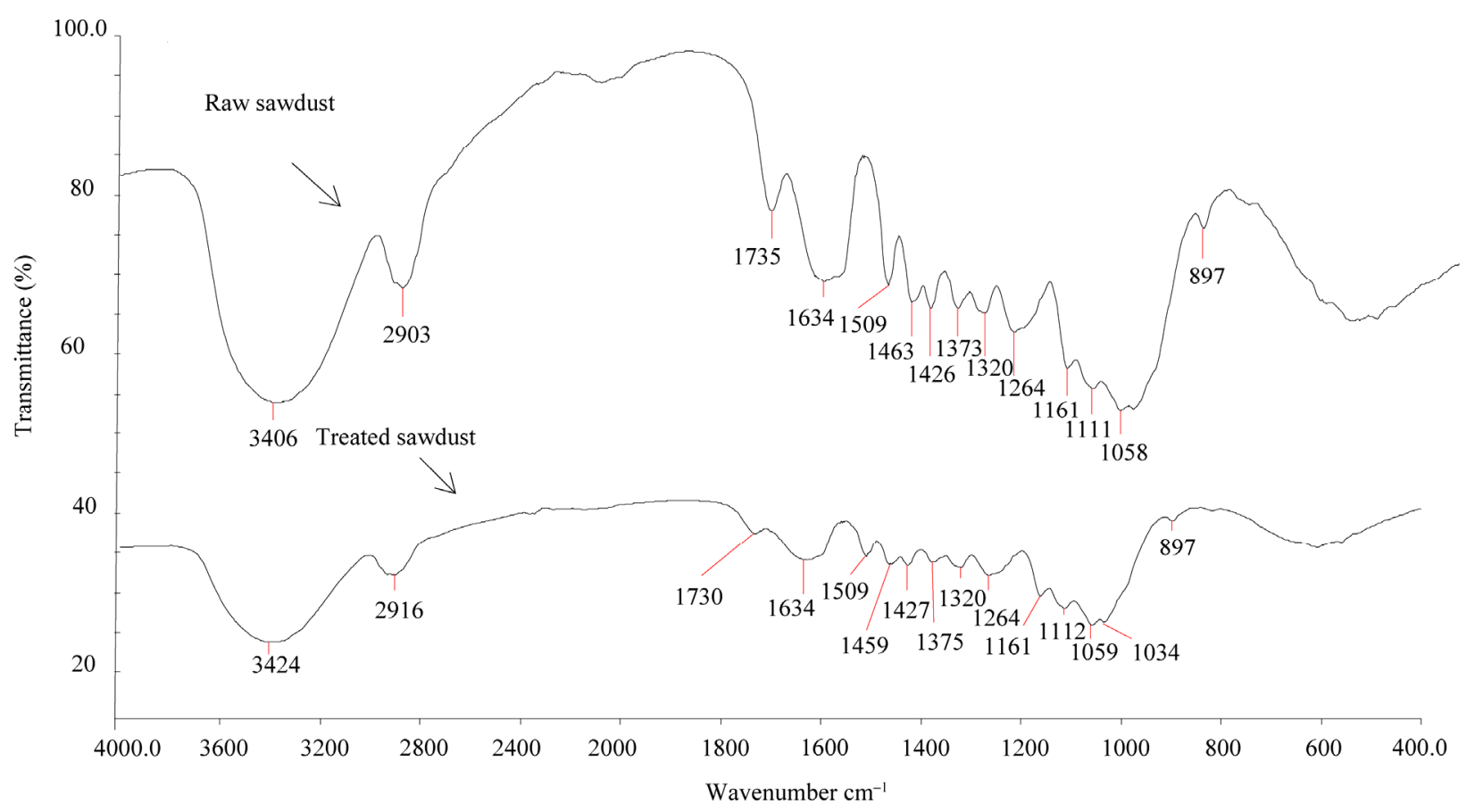

Figure 1. FTIR spectra of raw and treated wood sawdust. 


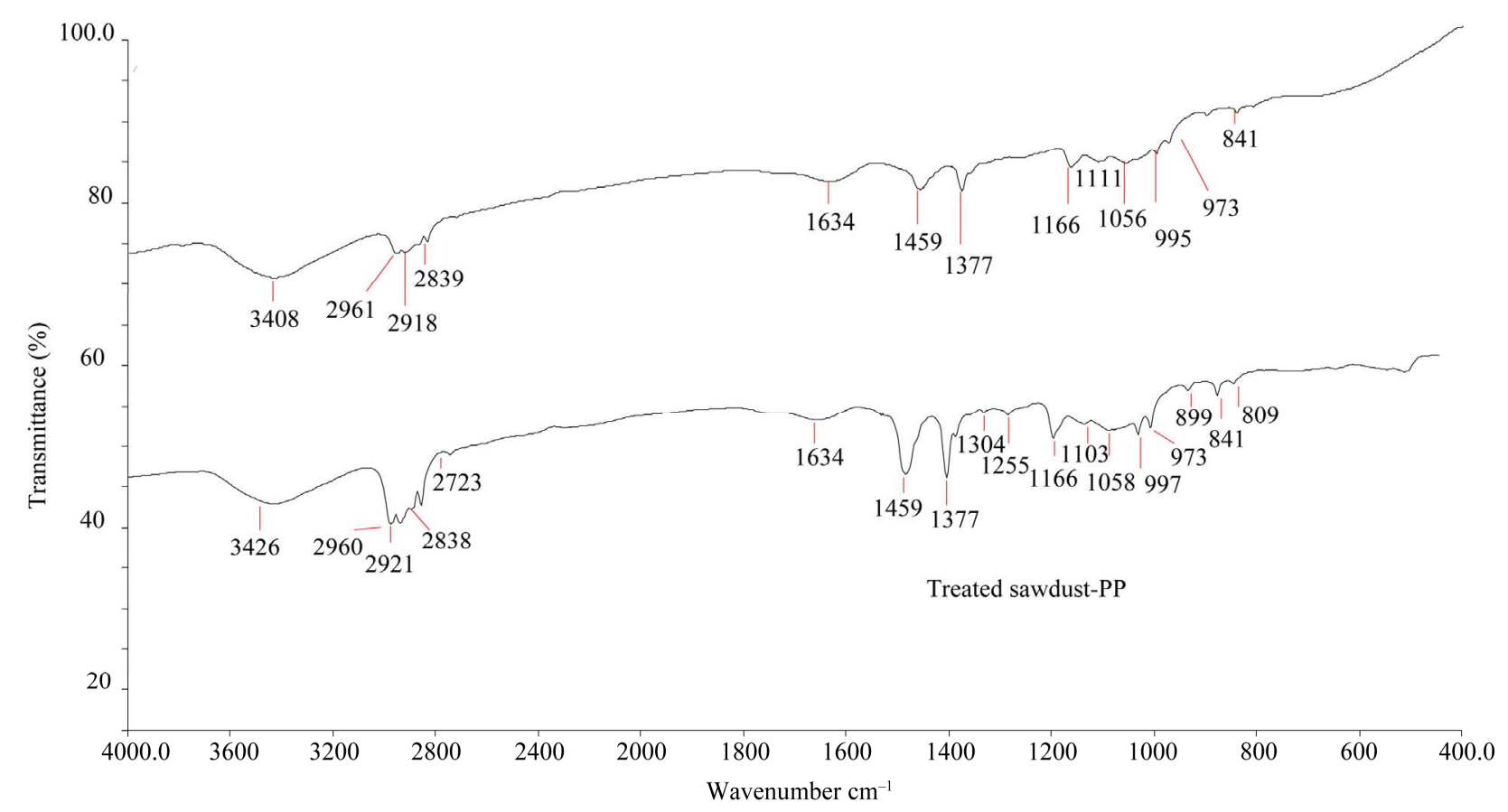

Figure 2. FTIR spectra of the raw sawdust-PP composites and treated sawdust-PP composites.
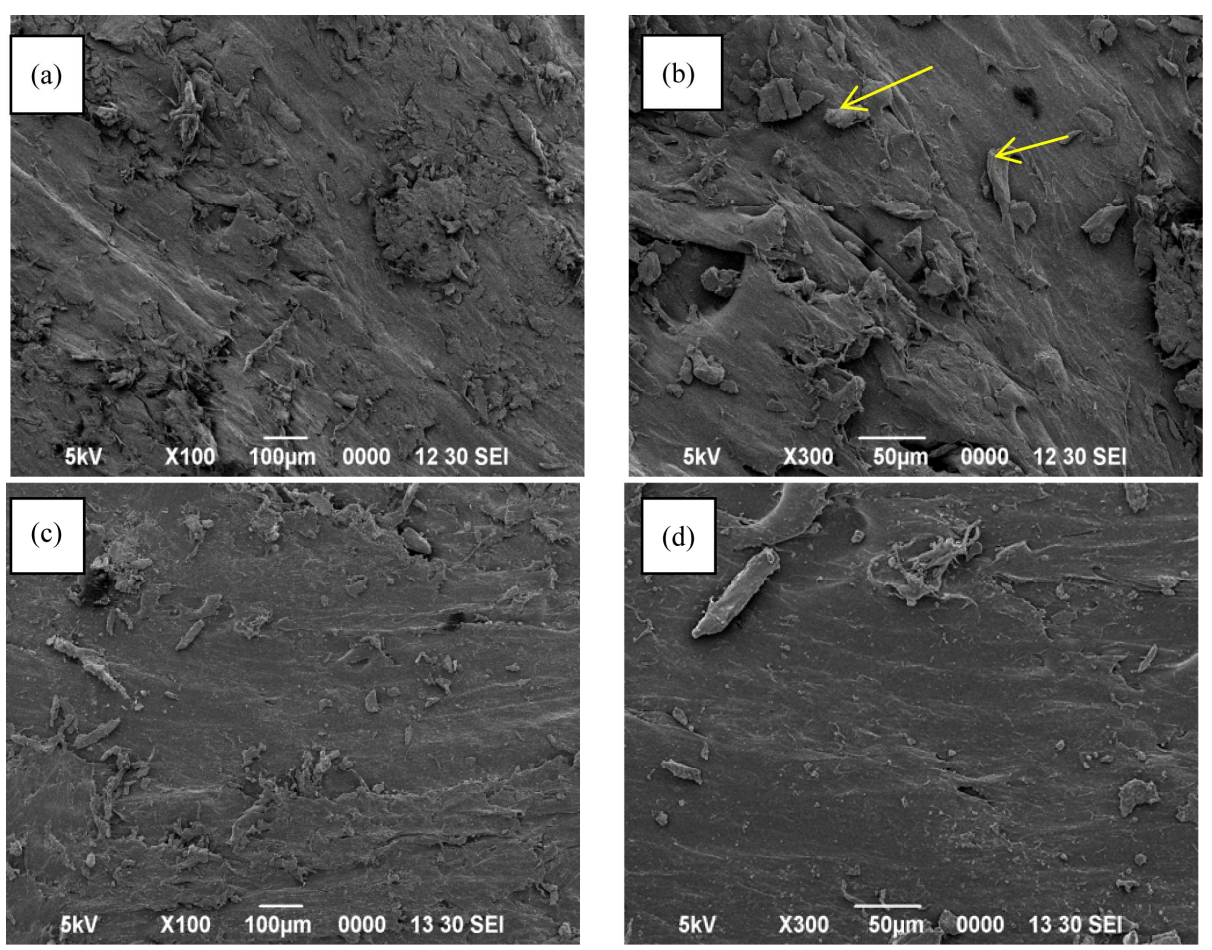

Figure 3. SEM Morphology of the PP reinforced with 30\% raw sawdust (a)-(b) and treated sawdust (c)-(d).

This also can show that the modified sawdust composites will absorbed substantially less water after immersion than raw ones. The uneven layer of lignocellulose materials were reduces after the chemical treatment that will lead to better mechanical properties.

\subsection{Mechanical and Physical Properties of LWPC}

The flexural and tensile properties were explained in this section. 


\subsubsection{Flexural Properties}

Flexural strength and modulus of raw and treated sawdust composites at different filler loading are shown in Figures $\mathbf{4}$ and 5 respectively. The result showed that the flexural strength increased with increased in filler loading [15]. All the treated sawdust composites showed higher flexural strength than the raw sawdust composites. Furthermore, from Figure 5, the flexural modulus is increased with filler loading increased which is in agreement with the other researcher $[15,21,22]$. It is found that the flexural strength decreased approximately $1.6 \%$ respectively over the raw sawdust-PP composites at 10 $w t \%$ filler loading, while for the $15 \mathrm{wt} \%$ - $25 \mathrm{wt} \%$ filler loading, the flexural strength gradually increase approximately from $6.6 \%-10.8 \%$ respectively. However at 30 $\mathrm{wt} \%$ raw sawdust-PP composite the flexural strength slightly decreased approximately $1.6 \%$ than the $25 \mathrm{wt} \%$ filler loading. This showed that, with the small incorporation of small amount of wood sawdust, at $10 \mathrm{wt} \%$. filler loading, the flexural strength of the composite was lowest than the raw PP. When the sawdust loadings increased, the flexural strength gradually increased which is due to the increased in resistance to shearing in the

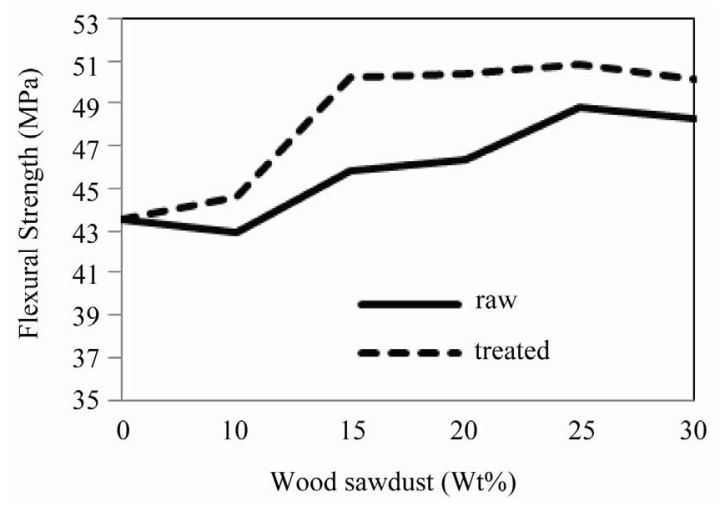

Figure 4. Flexural properties of composites at different filler loadings.

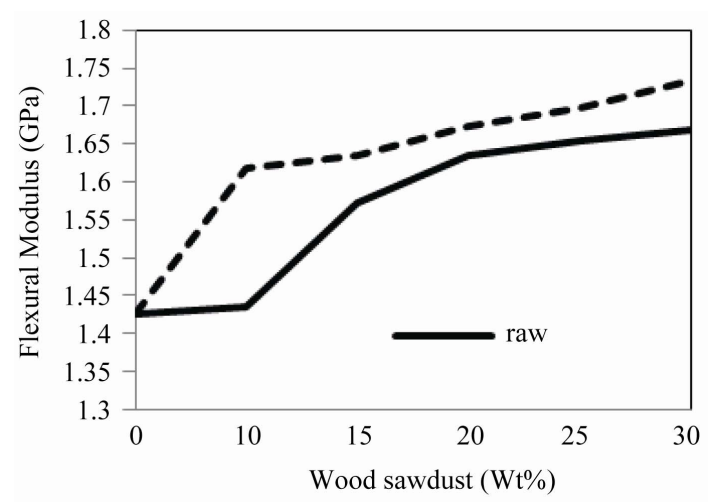

Figure 5. Flexural modulus of raw and treated sawdust/PP composites at different filler loading. composites structure probably because the presence of the fibers. Meanwhile in the treated sawdust-PP composites the increment was $2.3 \%-16.6 \%$ at filler loading from $10 \mathrm{wt} \%$ up to $25 \mathrm{wt} \%$. After that at $30 \mathrm{wt} \%$ treated sawdust, the flexural strength showed slightly decreased about $1.57 \%$.

The adding of both raw and treated sawdust has significantly increased both flexural strength and modulus of the composites. Since wood fibers have high modulus properties, hence higher fiber concentration required higher stress for the same deformation. The increased in fillermatrix adhesion was increased the stress transfer from the matrix to the filler. Meaning that, increased in the flexural modulus will attribute to the better incorporation of rigid sawdust into matrix polymer PP.

\subsubsection{Tensile Strength}

The properties of tensile strength and Young's modulus of both raw and treated sawdust-PP composites at different filler loading are shown in Figures 6 and 7. From Figure 6, the tensile strength for raw and treated sawdust gradually decreased with an increase in filler loading from $10 \mathrm{wt} \%$ - $30 \mathrm{wt} \%$ [15]. The tensile strength decreased due to the increasing filler content in the composites was effected the interfacial strength become weak between the filler and matrix [15,21.23]. But the treated sawdust showed slightly higher than raw one at all filler loading. Indicating that, the chemical treatment had improved the tensile strength of the composites. The sawdust was treated with with 2-ethylehexyl methacrylate in order to improve the mechanical properties of the composites. The weak interfacial adhesion between the hydrophilic sawdust and hydrophobic PP matrix and high water absorption is caused by the hydroxyl group in the raw sawdust. Basically there are three hydroxyl groups present in the cellulose anhydroglucose unit. One is primary hydroxyl group at $\mathrm{C}_{6}$ and the other two secondary hydroxyl groups at $\mathrm{C}_{2}$ and $\mathrm{C}_{3}$. In this research, the 2-ethylhexyl methacrylate breaks the hydroxyl groups at $\mathrm{C}_{2}$ positions during the reaction. This convert the $\mathrm{OH}$ groups at $\mathrm{C}_{2}$ become $\mathrm{C}_{11} \mathrm{H}_{18} \mathrm{O}_{2}$ as illustrated in Scheme 1 . The FTIR spectroscopic analysis confirmed this phenomenon occurs in Figure 2. Furthermore, the interfacial bonding between sawdust and the PP matrix significantly improved in the composites due to the replacement of the hydroxyl groups at $\mathrm{C}_{2}$ in the treated sawdust even the value is lower compare with the net PP $[15,24]$.

Figure 7 shows the variation of the Young's modulus at different fiber loading. The Young's modulus show increased with fiber loading from $10 \mathrm{wt} \%-30 \mathrm{wt} \%$ is in agreement with other researcher [15,24]. It is expected because the incorporation of rigid sawdust into the soft thermoplastics was occurred. Treated sawdust-PP composites exhibit higher values of Young's modulus than 


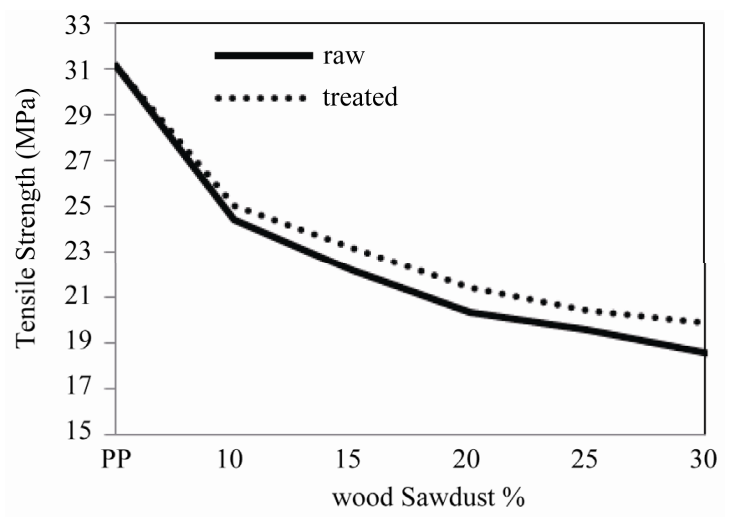

Figure 6. Tensile strength of $P P$ composites of raw and treated sawdust at different filler loading.

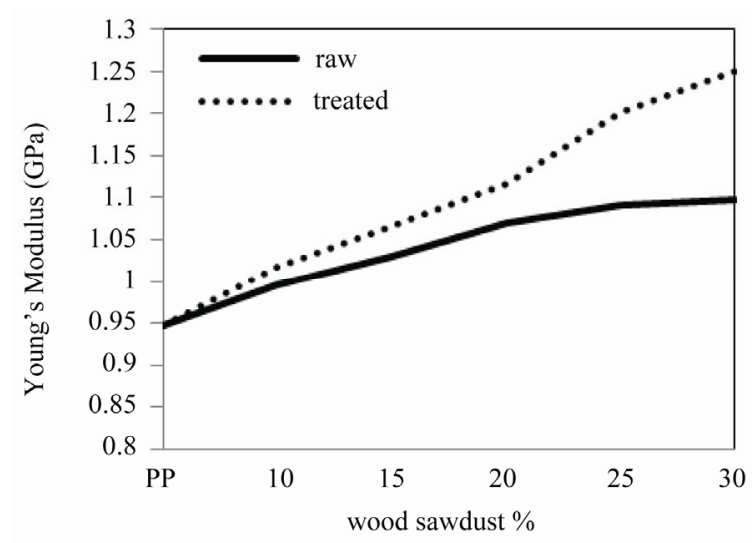

Figure 7. Variation of the Young's modulus of sawdust-PP composites at different filler loading.

raw composites. According to another researcher who obtained the same result reported that crystallites possess higher modulus compare those of amorphous substances $[5,8]$. The higher value of Young's modulus was achieved by treated sawdust at $30 \mathrm{wt} \%$ filler loading at $1.25 \mathrm{GPa}$, however raw sawdust were at $1.1 \mathrm{GPa}$.

During chemical treatment with the monomer, the sawdust surface probably attains somewhat crystalline nature, which might be dominated over its bulk nature, thus give higher modulus of the treated sawdust-PP composites. Meanwhile, the matrix mobility were decreased due to the incorporation of rigid fiber into the soft matrix hence make the composites more stiffness. These consequently increase the tensile strength of the treated sawdust at different filler loading such as $2.7 \%, 4.5 \%, 4.9 \%$, $4.6 \%$ and $7 \%$ increased at $10,15,20,25$ and $30 \mathrm{wt} \%$ respectively compare to raw one.

\subsubsection{Hardness Test}

Figure 8 shows the average values of hardness of the composites at various sawdust filler loading. "Hardness" is a general term which describes a combination of pro-

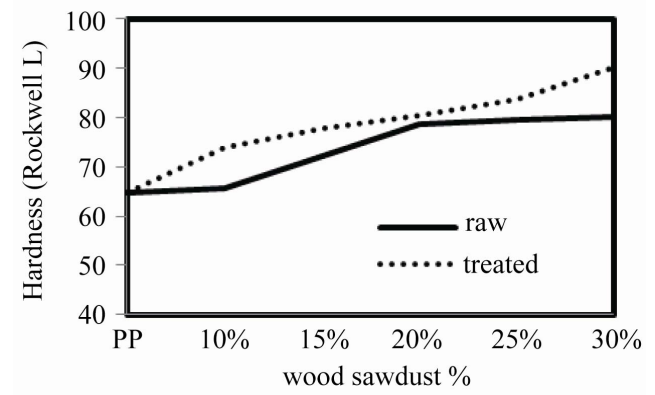

Figure 8. Variation of hardness of the raw and treated sawdust-PP composites at different filler loading.

perties, such as the resistance to surface indentation, abrasion, and scratching. In this study, hardness was a measure of resistance to indentation and the values obtained were used to evaluate the mechanical strength of each composite.

The hardness both raw and treated sawdust-PP composites increased with an increased in the fiber loading. It is observed that the treated sawdust exhibited better hardness compared to raw ones at all filler loading from $10 \mathrm{wt} \%$ - $30 \mathrm{wt} \%$ [24]. Further, there was considerable improvement in the hardness for the treated sawdust-PP composites. This phenomenon could be attributed to the better adhesion of the polymer to the sawdust fibre brought about by the chemical treatment [25]. The highest is observed at $30 \mathrm{wt} \%$ filler loading for both raw and treated which is at 80.2 and 90.2 Rockwell. This could be attributed because the good dispersion formed between the matrix and the filler beside the reducing of voids and stronger interfacial bonding between the fiber and matrix. The decreased of flexibility and increase of stiffness of the respective composites enhance the hardness properties as reported by other researcher [15].

\subsubsection{Water Absorption}

Figure 9 shows the water absorption characteristic for the raw and treated sawdust-PP composites against filler loading.

The water absorption ( $w \mathrm{t} \%)$ for the raw and treated sawdust composites, were varies depending on the filler loading. From the observation, the water absorption of composites increased gradually with an increase in filler loading $[15,19,23]$. This is due to the higher contents of filler loading in the composites that can absorb more water. When the content of wood sawdust increase in the composite, the number of free -OH groups is contain more from the cellulose and hemicellulose inside the fiber responsible for increase the water absorption. These free -OH or hydroxyl groups come in contact with water and form hydrogen bonding, which result in weight gain in the composites. In contrast, the treated sawdust-PP 


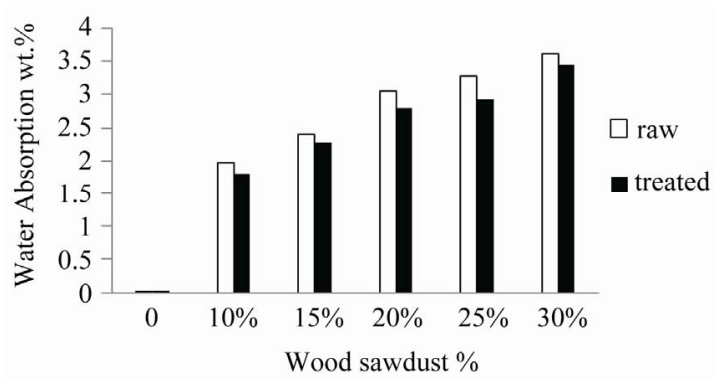

Figure 9. Variation of Water absorption of the raw and treated sawdust-PP composites at different filler loading after 16 days in $24 \mathrm{Hr}$ soaking in water.

composites exhibits the lowest water absorption compare to raw one at all filler loading. This implies that the chemical treatment had removed some -OH groups inside the cellulose thus reduces the number of free -OH groups inside the composites resulted in lower availability or the hydrophilic characteristic to absorb water for all the treated composites.

Meaning that, the fewer free hydroxyl groups in treated sawdust-PP composites attributed to the lower water absorption. From the result, neat PP showed the lowest water absorption followed by composites with $10 \%$ wt. filler loading up to $30 \mathrm{wt} \%$ filler loading. Composite with high filler contents (30 wt\%) exhibit highest water absorption for both raw and treated saw- dust-PP composites due to increase number of micro voids on the surface which is caused by the bigger amount of poor bonded area between the hydrophilic sawdust and hydrophobic matrix polymer which also refer to the decrease in density of the composites from Table 1. Thus water is easily entered through these voids [2]. Another reason of less water content of the treated sawdust composites is good interaction between the matrix and treated sawdust that resulted in void minimization in the resultant composites [24].

\subsubsection{Thickness Swelling Test}

The result of thickness swelling (TS) test was shown in Table 1. However in Figures 10 and $\mathbf{1 1}$ shows the thickness swelling behaviour of the composites. The TS of composites was mainly exposure of the sawdust fiber on the surface of the composites. TS of the composites were carried out for several hours until a constant weight was obtain. In this study, thickness swelling of composites was carried out for 24 hour in about 16 days. It was observed that the TS for all composites increase as the filler loading (sawdust content) increased inside the composites. The result showed that the thickness swelling was the highest for the $30 \mathrm{wt} \%$ raw sawdust-PP $(0.69 \%)$, which corresponded to the highest water absorption (Table 1 and Figure 9). In a similar manner to the water absorption, the thickness swelling increased with sawdust
Table 1. Data for physical properties of the composites.

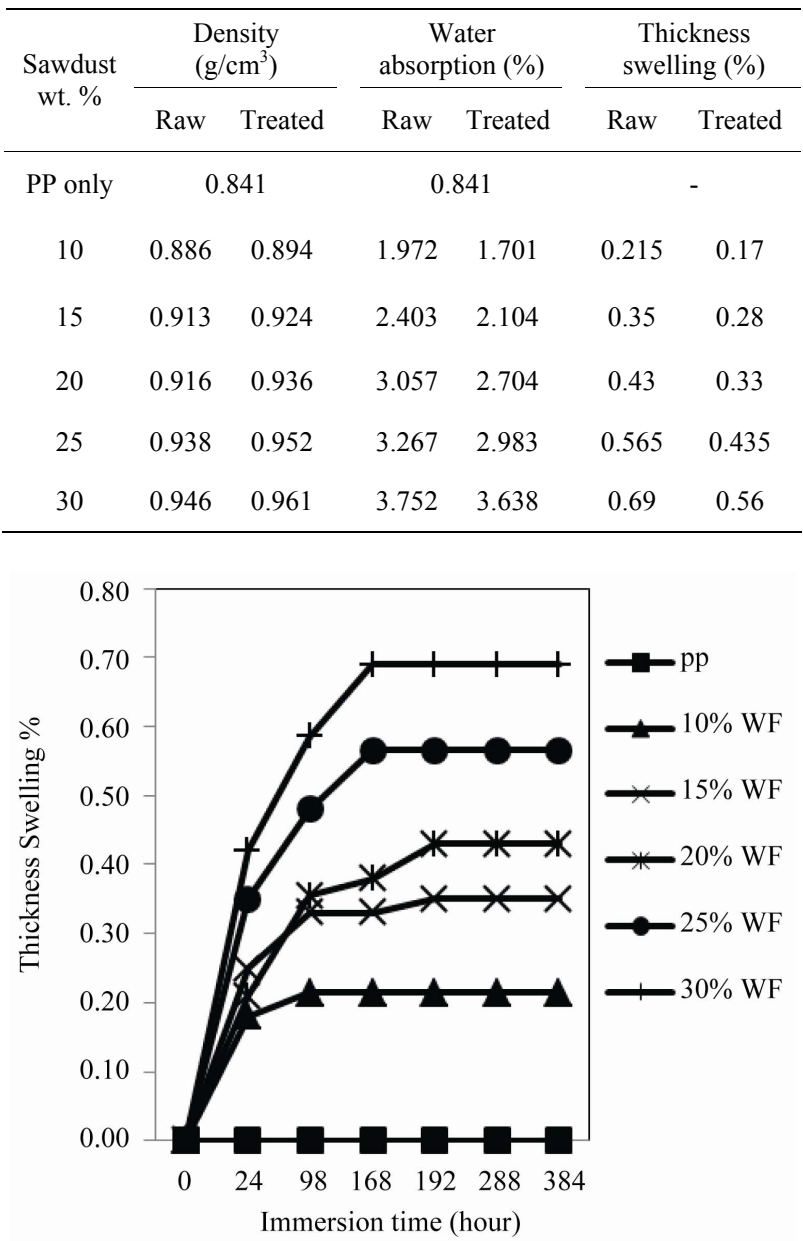

Figure 10. Thickness swelling versus water immersion time for raw wood-flour-PP composites.

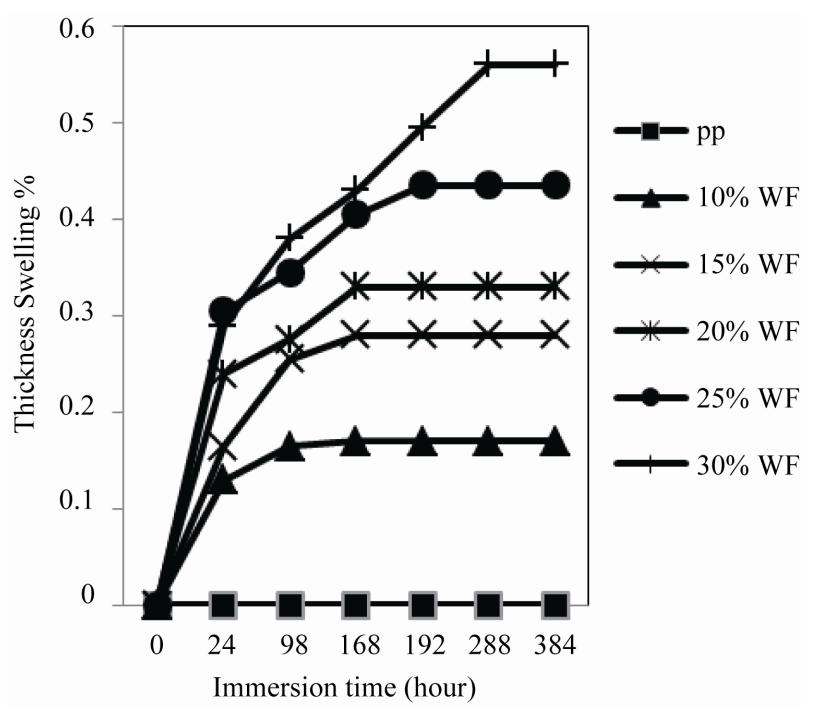

Figure 11. Thicknesses swelling versus water immersion time for treated wood-flour-PP composite. 
content for both raw and treated sawdust-PP composites. Table 1 showed all treated sawdust-PP composite exhibit lower thickness swelling than the raw one. At 10, 15, 20, 25 and $30 \mathrm{wt} \%$ sawdust, the thickness swelling gradually decrease after chemical treatment from $0.215 \%$ to $0.17 \%$, from $0.35 \%$ to $0.28 \%$, from $0.43 \%$ to $0.33 \%$, from $0.565 \%$ to $0.435 \%$ and from $0.69 \%$ to $0.56 \%$ respectively.

This indicates that the raw composites possess high porosity or the presence of void on the surface of raw composites. This is responsible for the changes in dimension of cellulose-based composites, particularly in the thickness, and the linear expansion due to reversible and irreversible swelling of the composites [26]. Meanwhile in contras the pure PP show the lowest TS (\%) which is $0 \%$. In other words there were no TS in the PP composites due to nature of PP as water resistant. It was also indicated that, TS values of composite increase with an increase of water absorption time. When the composites exposed to the water immersion time increased, a significant amount of water absorbed, resulting in the swelling of the fiber. Hence the swelling of the fiber gives stress on the surrounding.

\subsubsection{Density of Composite}

It is observed from the Table 1, density of sawdust-PP composites for raw and treated was increased as the sawdust $w t \%$ loading increased. The highest was at treated sawdust $30 \mathrm{wt} \%$ which is $0.961 \mathrm{~g} / \mathrm{cm}^{3}$ respectively compare to raw one, $0.946 \mathrm{~g} / \mathrm{cm}^{3}$.

It is observed that, all raw sawdust-PP composites have lower density compare to raw as the fiber increase. This shows that there was present of voids inside the raw composites. After the chemical treatment, better interaction between the matrix and the fiber were exist hence had resulted in void minimization in the composites. As the fiber increase, the number of voids increases as more fiber and matrix leak out during the curing step thus create void inside the composites.

\section{Conclusions}

In this work, raw sawdust was chemically treated with 2-ethylhexyl methacrylate in order to remove some amount of hydroxyl groups in cellulose and improved the adhesion between the matrix and fiber. It is observed that the tensile strength of the composites of raw and treated sawdust is decrease with increasing filler loading. The values of the Young's modulus, flexural strength, flexural modulus, and hardness are found to increase with an increase in filler loading and the values are found to be higher for treated sawdust-PP composites than the raw ones. Hence, meaning that treated sawdust attributed to better dispersion of the filler in the matrix and stronger filler-matrix interfacial adhesion. The difference in the filler-matrix interfacial adhesion between the filler and the matrix for raw and treated sawdust reinforced composites is clearly seen in the SEM micrographs. The improved mechanical properties of the treated sawdust-PP composites are supported by SEM images that show better filler-matrix adhesion compared to raw ones. Water absorption increased with filler loading however, treated sawdust-PP composites showed the lowest water absorption and thickness swelling compared to raw composites, showing that the chemical treatment of sawdust has considerably reduced the hydrophilic nature of the sawdust.

\section{Acknowledgements}

The authors would like to thank the University Malaysia Sarawak (UNIMAS) for providing the sponsorship under FRGS research grant (UNIMAS/ FGRS/02(20)/741/2010 [27] that has made this work possible.

\section{REFERENCES}

[1] A. K. Bledzki and J. Gassan, "Composites Reinforced with Cellulose Based Fibres," Progress in Polymer Science, Vol. 24, No. 2, 1999, pp. 221-274. doi:10.1016/S0079-6700(98)00018-5

[2] H. S. Yang, H. J. Kim, H. J. Park, B. J. Lee and T. S. Hwang, "Water Absorption Behavior and Mechanical Properties of Lignocellulosic Filler-Polyolefin Bio-Composites," Composite Structures, Vol. 72, No. 4, 2006, pp. 429-437.doi:10.1016/j.compstruct.2005.01.013

[3] I. Ahmad and T. M. Mei, "Mechanical and Morphological Studies of Rubber Wood Sawdust-Filled UPR Composite Based on Recycled PET," Journal of Polymer-Plastics Technology and Engineering, Vol. 48, No. 12, 2009, pp. 1262- 1268 .

doi:10.1080/03602550903204105

[4] A. K. Rana, A. Mandal, and S. Bandyopadhyay, "Short Jute Fiber Reinforced Polypropylene Composites: Effect of Compatibiliser, Impact Modifier and Fiber Loading," Composites Science and Technology, Vol. 63, No. 6, 2003, pp. 801-806. doi:10.1016/S0266-3538(02)00267-1

[5] A. R. Sanadi, D. F. Caulfield, R. E. Jacobson and R. M. Rowell, "Renewable Agricultural Fibers as Reinforcing Fillers in Plastics: Mechanical Properties," Industrial \& Engineering Chemistry Research, Vol. 34, No. 5, 1995, pp. 1889-1896. doi:10.1021/ie00044a041

[6] A. K. Bledzki, O. Faruk and V. E. Sperber, "Cars from Bio-Fibres," Macromolecular Materials and Engineering, Vol. 291, No. 5, 2006, pp. 449-457. doi:10.1002/mame.200600113

[7] A. K. Bledzki, M. Letman, A. Viksne and L. Rence, "A Comparison of Compounding Processes and Wood Type for Wood Fibre-PP Composites," Composites A, Vol. 36, No. 6, 2005, pp. 789-797. doi:10.1016/j.compositesa.2004.10.029

[8] A. Karmakar, S. S. Chauhan, J. M. Modak and M. 
Chanda, "Mechanical Properties of Wood-Fiber Reinforced Polypropylene Composites," Composites A, Vol. 38, No. 2, 2007, pp. 227-233.

[9] D. Maldas and B. V. Kokta, "Interfacial Adhesion of Lignocellulosic Materials in Polymer Composites: An Overview," Composite Interfaces, Vol. 1, No. 1, 1993, pp. 87-108. doi:10.1163/156855493X00338

[10] N. E. Marcovich, M. M. Reboredo and M. I. Aranguren, "Dependence of the Mechanical Properties of Wood Flour-Polymer Composites on the Moisture Content," Applied Polymer Science, Vol. 68, 1998, pp. 2069-2076. doi:10.1002/(SICI)1097-4628(19980627)68:13<2069::AI D-APP2>3.0.CO;2-A

[11] M. D. H. Beg and K. L. Pickering, "Fiber Pre-Treatment and Its Effects on Wood Fiber Reinforced Polypropylene Composites," Materials and Manufacturing Processes, Vol. 21, No. 3, 2006, pp. 303-307. doi:10.1080/10426910500464750

[12] M. N. Ichazo, C. Albano, J. Gonzalez, R. Perera and M. V. Candal, "Polypropylene/Wood Flour Composites: Treatments and Properties," Composites Structure, Vol. 54, No. 2, 2001, pp. 207-214. doi:10.1016/S0263-8223(01)00089-7

[13] N. M. Stark, "Wood Fiber Derived from Scrap Pallets Used in Polypropylene Composites," Forest Products Journal, Vol. 49, No. 6, 1999, pp. 39-46.

[14] J. Kuruvilla and T. Sabu, "Effect of Chemical Treatment on the Tensile Properties of Short Sisal Fibre-Reinforced Polyethylene Composites," Polymer, Vol. 37, No. 23, 1996, pp. 5139-5149. doi:10.1016/0032-3861(96)00144-9

[15] Md. Rezaur Rahman, Md. Nazrul Islam, Md. Monimul Huque, "Influence of Fiber Treatment on the Mechanical and Morphological Properties of Sawdust Reinforced Polypropylene Composites," Composites: Part A, Vol. 18, No. 3, 2010, pp. 1739-1747.

[16] ASTM Standard D 638-01, "Test Methods for Tensile Properties of Plastics," In: Annual Book of ASTM Standard, Ed., American Society of Testing and Materials, Vol. 8, No. 1, 2002, pp. 45-57.

[17] ASTM Standard D 790, "Test for Flexural Properties of Unreinforced and Reinforced Plastics and Electrical Insulating Materials," 2000.

[18] ASTM Standard D 785-98, "Test Method for Rockwell Hardness of Plastic and Electrical Insulating Materials,"
In: Annual Book of ASTM Standard, Ed., 2002.

[19] H. Ismail, M. Edyhan, and B. Wirjosentono, "Bamboo Fiber Filled Natural Rubbercomposites; The Effects of Filler Loading and Bonding Agent," Journal of polymer Testing, Vol. 21, 2002, pp. 139-144.

[20] B. Smith, "Infrared Spectra of Polymers: Polypropylene," B. Smith, "Infrared Spectral Interpretation: A Systematic Approach," CRC Press, New York, 1999.

[21] C. W. Lou, C. W. Lin, C. H. Lei, K. H. Su, C. H. Hsu, Z. H. Liu and J. H. Lin, "PET/PP Blend with Bamboo Charcoal to Produce Functional Composites," Journal of Materials Processing Technology, Vol. 192-193, 2007, pp. 428-433. doi:10.1016/j.jmatprotec.2007.04.018

[22] S. Joseph, M. S. Sreekala, Z. Oommen, P. Koshy and S. A. Thomas, "Comparison of Mechanical Properties of Phenol Formaldehyde Composites Reinforced with Banana Fibers and Glass Fiber," Composites Science and Technology, Vol. 62, No. 14, 2002, pp. 1857-1868. doi:10.1016/S0266-3538(02)00098-2

[23] H. S. Lee, D. Cho and S. O. Han. "Effect of Natural Fiber Surface Treatments on the Interfacial and Mechanical Properties of Henequen/Polypropylene Biocomposites," Macromolecular Research, Vol. 16, No. 5, 2008, pp. 411417. doi:10.1007/BF03218538

[24] M. R. Rahman, M. M. Huque, M. N. Islam and M. Hasan, "Improvement of Physico-Mechanical Properties of Jute Fiber Reinforced Polypropylene Composites $\mathrm{Bu}$ postTreatment," Composites: Part A, Vol. 39, No. 11, 2008, pp. 1739-1747. doi:10.1016/j.compositesa.2008.08.002

[25] S. B. Elvy, G. R. Dennis and N. Loo-Teck, "Effects of Coupling Agent on the Physical Properties of WoodPolymer Composites," Journal of Materials Processing Technology, Vol. 48, No. 1-4, 1995, pp. 365-372. doi:10.1016/0924-0136(94)01670-V

[26] H. P. S. Khalil-Abdul, A. M. Issam, M. T. Ahmad-Shakri, R. Suriani and A.Y. Awang, "Conventional Agro-composites from Chemically Modified Fibres," Industrial Crops and Products, Vol. 26, No. 3, 2007, pp. 315-323. doi:10.1016/j.indcrop.2007.03.010

[27] G. E. Myers, "Wood Flour and Polypropylene or High Density Polyethylene Composites: Influence of Maleated Polypropylene Concentration and Extrusion Temperature on Properties," International Journal of Polymeric Materials, Vol. 15, 1999, pp. 171-186. doi:10.1080/00914039108041082 